\title{
PRESERVED LEARNING IN MONKEYS WITH MEDIAL TEMPORAL LESIONS: SPARING OF MOTOR AND COGNITIVE SKILLS ${ }^{1}$
}

\author{
STUART ZOLA-MORGAN ${ }^{2}$ AND LARRY R. SQUIRE \\ Veterans Administration Medical Center, San Diego and Department of Psychiatry, University of California, School of Medicine, \\ La Jolla, California, 92093
}

December 16, 1982; Revised October 25, 1983; Accepted October 28, 1983

\begin{abstract}
In an effort to bring into correspondence the findings from human amnesic patients and the findings from monkeys with surgical lesions of those brain regions thought to be affected in the human cases, we have addressed in three experiments the implication of findings that human amnesia spares motor and cognitive skills. In the first experiment, monkeys with conjoint lesions of hippocampus and amygdala $(\mathrm{H}-\mathrm{A})$, which reproduced the surgical removal sustained by the noted amnesic case $H$. M., were only mildly impaired in learning relatively difficult pattern discrimination tasks. Monkeys with lesions of temporal stem matter (TS) were severely impaired on the same tasks, due to an apparent deficiency in visual information processing. In the second experiment, monkeys with $\mathrm{H}$-A lesions were severely impaired at learning relatively easy discrimination tasks that could be acquired rapidly by normal monkeys. Monkeys with TS lesions were not impaired. In the third experiment, monkeys with $\mathrm{H}$-A lesions exhibited normal acquisition of two motor skill tasks. These data can be understood in the light of a distinction between kinds of memory, founded in recent studies of the neuropsychology of human amnesia. These studies have led to a distinction between the learning of skills or procedures, which is spared in human amnesia, and the learning of facts and episodes, which is impaired. Monkeys with $\mathrm{H}-\mathrm{A}$ lesions are normal at skill learning like human amnesic patients with similar lesions. This conclusion depends in part on the argument developed here that pattern discrimination learning, as accomplished by monkeys, has a large skilllike component. These results bring into correspondence the behavioral data from human amnesic patients and operated monkeys and set the stage for identifying precisely what brain structures must be damaged to produce amnesia.
\end{abstract}

Neuropsychological analysis of amnesia in man has provided useful information about how the brain accomplishes learning and memory (for reviews, see Baddeley, 1982; Cermak, 1982; Squire, 1982; Weiskrantz, 1982). Neuropathological information has further indicated that amnesia occurs following damage to the medial

\footnotetext{
${ }^{1}$ Supported by the Medical Research Service of the Veterans Ad ministration and National Institute of Mental Health Grant MH24600. We thank Dr. Mort Mishkin for preparation of the operated animals, Carol Micheletti and Janet Kurz for the preparation of the brain tissue, Dr. David Amaral for histological evaluation, Brian Leonard and Ellen Bulder for behavioral testing, and Dr. Peter Graf for comments on the manuscript.

${ }^{2}$ To whom correspondence should be addressed, at Veterans Administration Medical Center, V116A, 3350 La Jolla Village Drive, San Diego, CA 92161.
}

temporal region or to the midline diencephalic region (Scoville and Milner, 1957; Barbizet, 1970; Victor et al., 1971). Because of these findings in man, there has been interest in the possibility of establishing a model of the human syndrome in experimental animals, especially in the monkey. Animal models of human amnesia could identify with certainty which brain regions must be damaged to produce amnesia, and they could lead to more detailed neurobiological studies of learning and memory. Recent studies in monkeys have had some success at achieving an animal model. Behavioral tasks have been identified for the monkey that are sensitive to human amnesia, and progress has been made in identifying critical brain regions that when damaged produce impairment on these same tasks (Gaffan, 1974; Mishkin, 1978, 1982; Mahut et al., 1981, 1982; Moss et al., 1981; 
S. Zola-Morgan and L. R. Squire, submitted for publication; for review, see Squire and Zola-Morgan, 1983).

Recent studies of human amnesia have shown that the memory impairment is not as global as once believed. Specifically, it has become clear that human amnesia affects some forms of learning and memory but not others. Not only is the capacity to acquire motor skills and perceptuomotor skills spared in amnesia, as described some 20 years ago (Milner, 1962; Corkin, 1968), there is also preservation of the ability to acquire cognitive skills, including mirror reading and the solution to certain puzzles (Cohen and Squire, 1980; Cohen and Corkin, 1981). For example, amnesic patients can acquire and maintain in a normal fashion the skill of reading words from a mirror-reversed display, yet they do not remember either the particular words that were read or the fact that the skill had been practiced on previous occasions. When taught just prior to a course of bilateral electroconvulsive therapy (ECT), this same mirror-reading skill survives intact, although patients have retrograde amnesia for the learning experience (Squire et al., 1984). These data have suggested to us a distinction between memory for facts and episodes, which is impaired in amnesia, and memory for skills or procedures, which is intact (declarative versus procedural memory (Cohen and Squire, 1980; Squire, 1982; Cohen, 1984).

This selective feature of human amnesia has not been addressed systematically in work with monkeys. Successful learning of perceptuomotor skills by amnesic patients suggests that monkeys with damage to brain regions implicated in human amnesia should also be able to acquire perceptuomotor skills. In addition, the finding of preserved cognitive skill learning in human amnesia might help resolve a long-standing puzzle about the work with monkeys: Monkeys with medial temporal damage generally perform well on visual discrimination tasks. Visual discrimination tasks, which require learning to respond differentially to two simultaneously presented stimuli, have been widely used in the study of learning and memory in animals (Spence, 1936; Lashley, 1938; Harlow, 1944, 1950). These tasks can take hundreds of trials and many daily sessions to learn, suggesting that they require the capacity for long-term retention that is impaired in amnesia. Yet, monkeys with medial temporal lesions are usually successful in learning visual discrimination tasks, and this finding has been a reason for supposing that their behavioral impairment cannot be reconciled with the amnesia in humans produced by comparable lesions (Orbach et al., 1960; also see Squire and Zola-Morgan, 1983).

It is possible that successful skill learning by amnesic patients and the visual discrimination learning achieved by monkeys with medial temporal lesions have important features in common. This view was first advanced by Iversen (1976): “. . . in everyday human learning there are no strict counterparts of discrimination tasks in which the same piece of information is repeated ad nauseam. In humans, motor learning perhaps comes closest to this ..." (pp. 15-16). Most theories of simultaneous discrimination learning involve two processes (Zeaman and House, 1963; Lovejoy, 1968; Sutherland and Mackintosh, 1971) and suggest that a major part of the learning may be acquired as a skill. Animals must come to attend to the appropriate stimulus dimension, i.e., the animal must identify how two stimuli are different and which differences are relevant to the task. This differentiation is accomplished gradually, day by day, often requiring hundreds of trials, and learning improves progressively from chance to higher levels of performance. A second part of discrimination learning is considered to be identifying which stimulus is the rewarded one. But for discrimination learning that develops gradually over many days of repeated trials, this process is secondary to the gradual tuning in of the appropriate stimulus dimension. By this formulation, monkeys with medial temporal lesions might succeed at discrimination learning just as human patients are able to learn skills.

The present study tested these ideas about visual discrimination learning, skill learning, and amnesia in three separate experiments. In the first experiment, involving visual pattern discrimination learning, it was supposed that learning should be gradual and show progressive improvement across many days, as it does in motor skill learning and cognitive skill learning in humans. Moreover, since discrimination learning should involve components that are not skill-like (e.g., learning which stimulus is the rewarded one), visual discrimination learning in monkeys should be mildly impaired by medial temporal lesions. The impairment should reveal itself as a tendency to forget between daily sessions some of what has been learned previously. In the second experiment, we attempted to reduce the skill-like component of discrimination learning by using stimuli that could be readily differentiated. In this circumstance, the task should be easier for monkeys to learn. But now learning should depend primarily on components that are not skill-like, and medial temporal lesions should markedly impair discrimination learning. In the third experiment, we administered two motor skill tasks, similar to ones at which human amnesia patients can succeed. We predicted that medial temporal lesions should not affect the ability of monkeys to learn these tasks.

Monkeys were prepared with either medial temporal lesions which reproduced the surgical lesions of the noted amnesic patient H. M. (Scoville and Milner, 1957) or with lesions of the temporal stem, which are associated with known deficits in visual pattern discrimination learning (Horel and Misantone, 1976; Zola-Morgan et al., 1982). In all, 13 monkeys were tested, although not all monkeys took part in every experiment.

\section{Materials and Methods}

Subjects. The subjects were 13 adult cynomolgus monkeys (Macaca fascicularis) weighing 3 to $5 \mathrm{~kg}$. The intended lesions were bilateral conjoint removal of the hippocampus and the amygdala $(\mathrm{H}-\mathrm{A}=4)$ and bilateral lesions of temporal stem white matter $(\mathrm{TS}=5)$. Three monkeys served as an unoperated control group $(\mathrm{N}=3)$. One additional monkey was prepared as an operated control for the surgical approach used to produce the temporal stem lesion (TSC $=1$ ) and sustained bilateral damage limited to the cortex of the upper bank of the superior temporal sulcus. The present series of tests began approximately 4 months after surgery, at a time 
when all animals had identical testing histories. Their experience had consisted of training on a nonmatching to sample, object recognition task. This task and others of the same type are sensitive to human amnesia (Sidman et al., 1968; L. R. Squire and S. Zola-Morgan, unpublished data). The H-A monkeys with medial temporal damage were severely impaired; those with temporal stem damage were unaffected (Zola-Morgan et al., 1982). All animals were housed individually and were maintained on a diet of Purina Chow, supplemented daily with fruit. Feeding took place once a day, immediately following the testing session.

Surgery. All surgery was performed in a single stage under Nembutal anesthesia ( $25 \mathrm{mg} / \mathrm{kg}$ of body weight). Bilateral removal of $\mathrm{H}$-A was accomplished through four separate entries, two on each side of the brain. First, the amygdala was approached by elevating the frontotemporal junction and entering the brain at a point medial to the anterior tip of the rhinal sulcus. All gray matter anterior to the rostralmost portion of the hippocampus and medial to the white matter of the temporal lobe was then aspirated using a small-gauge sucker. Next, the hippocampus on the same side was approached by elevating the occipitotemporal convexity and entering the brain medial to the occipitotemporal sulcus and caudal to entorhinal cortex. The hippocampus and much of the underlying fusiform hippocampal gyrus was then removed. The upper surface of the lateral ventricle served as an identifiable dorsal boundary along the entire length of the removal. In this way it was possible to spare the TS during H-A surgery by not crossing the lateral ventricle.

Bilateral lesions of the temporal stem area were made through an opening along the upper bank of the superior temporal sulcus. The white matter underlying the fundus of the sulcus was then entered at a point about $15 \mathrm{~mm}$ caudal to the anterior tip of the temporal lobe, and the temporal stem was aspirated for approximately $5 \mathrm{~mm}$ caudally and $10 \mathrm{~mm}$ rostrally using the wall of the lateral ventricle as a visual guide. This surgical approach to the TS made it possible to spare the hippocampus because the ventricle was not crossed during surgery. One additional monkey (TSC) was prepared to control for the damage sustained to the upper bank of the superior temporal sulcus during TS surgery. This animal underwent the same surgical procedures as the five TS monkeys but did not sustain TS damage.

Histological verification of lesions. Upon completion of behavioral testing, operated monkeys were sacrificed, and their brains were fixed in sugar/formalin and embedded in albumin. Frozen sections were cut at $50 \mu$, and alternate sections were stained with thionin for cellular Nissl substance. All four monkeys in the H-A group sustained nearly complete bilateral removals of the amygdala and the hippocampus (Fig. 1). Although there was slight sparing in all monkeys of the anterior portion of the medial nucleus of the amygdala, in all cases the cells appeared shrunken and gliotic. The hippocampus was removed for its entire extent with the exception, in two animals, of the most posterior $2.5 \mathrm{~mm}$. In addition to the hippocampus and the amygdala, the lesions in all four monkeys also included the parahippocampal gyrus,

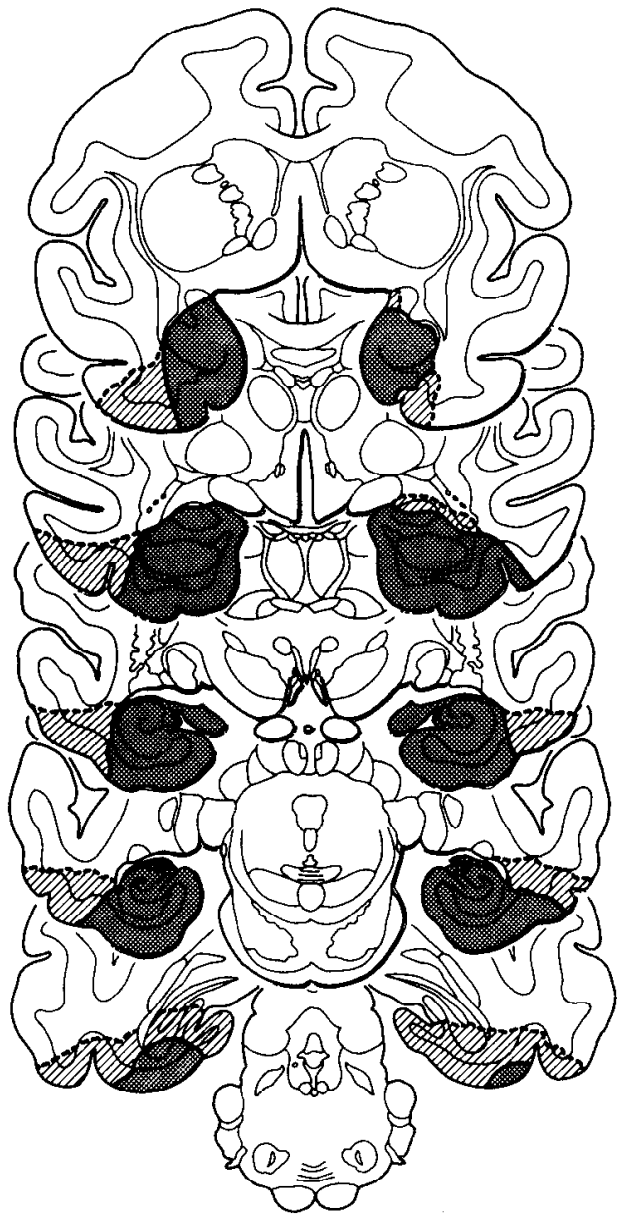

Figure 1. Representative coronal sections through the temporal lobe showing the smallest (dark) and the largest (striped) extent of damage in the four monkeys of the $\mathrm{H}$-A group. One monkey sustained substantial bilateral damage to area TE (approximately $50 \%$ on each side), and one monkey sustained unilateral damage to area TE. The involvement of TE in the other two animals was negligible. See the text for details.

including area TF-TH of von Bonin and Bailey (1947) and the entorhinal cortex. In one monkey the ventral half of the inferotemporal gyrus was damaged bilaterally for most of its anterior-posterior extent, and thus area TE in this animal was compromised. A second animal sustained significant damage to area TE for approximately $15 \mathrm{~mm}$ of its extent on one side but only negligible TE damage on the other side. In the remaining two animals, damage to TE was negligible. Neither the caudate nuclei, the lateral geniculate nuclei, nor the temporal stem sustained significant damage in any of the animals. The medial dorsal nuclei of the thalamus appeared normal, and there were no detectable abnormalities in the mammillary bodies. The fornix, which normally carries subicular input to the mamillary bodies, appeared gliotic throughout its extent.

In the five TS monkeys, the temporal stem white matter was transected bilaterally for approximately 15 $\mathrm{mm}$, starting from just behind the temporal pole and extending caudally to the midpoint of the lateral geniculate nucleus (Fig. $2 A$ ). In every animal the cortex of the upper bank of the superior temporal sulcus and the 


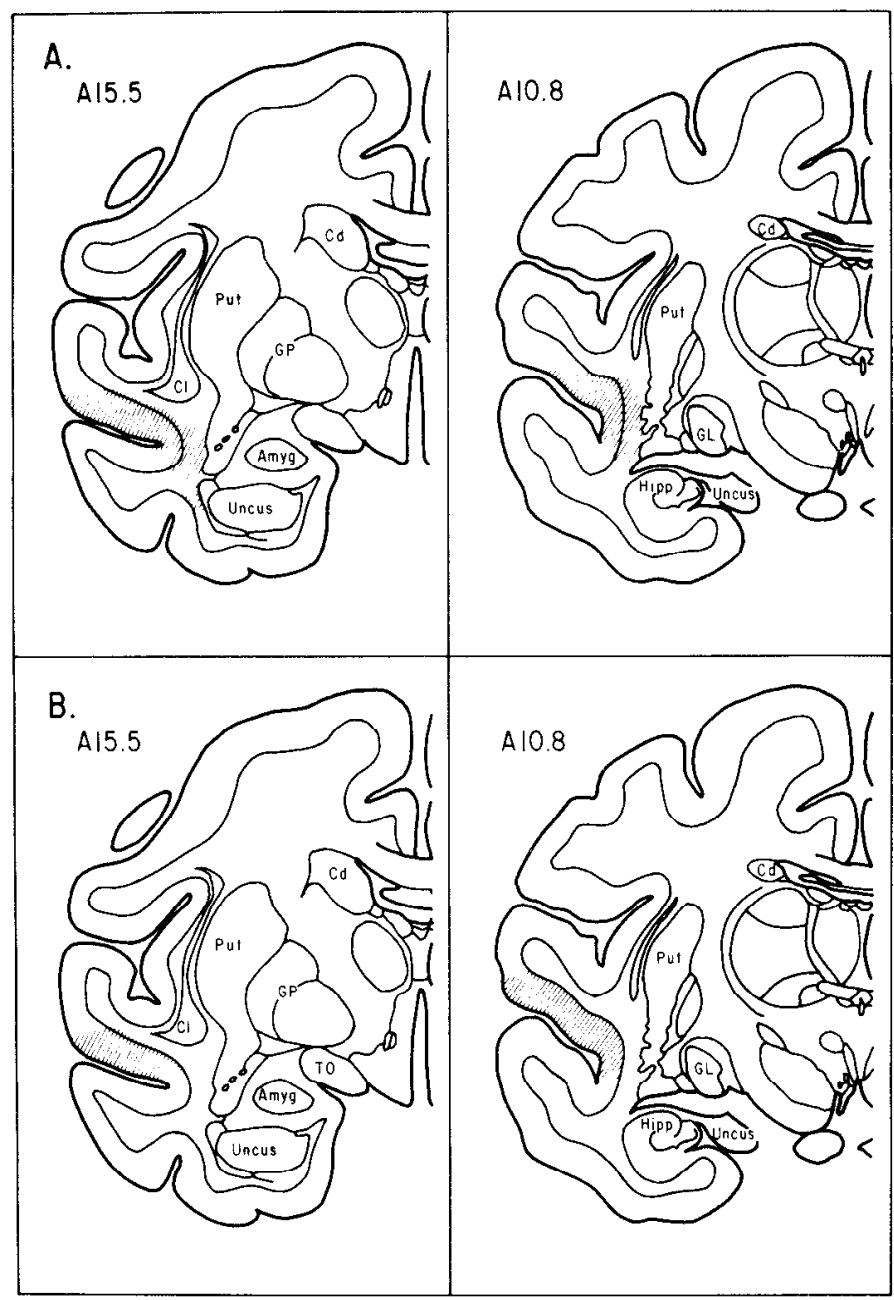

Figure 2. A, Two representative coronal sections from a monkey in the TS-group. The lesions in all five TS monkeys were comparable. $B$, Two sections from monkey TSC at the same levels as the TS monkey, prepared to control for the cortical damage sustained during temporal stem surgery. While only one hemisphere is shown, the damage was symmetrical throughout the extent of the brain. See the text for details. $A m y g$, amygdala; $C d$, caudate; $C l$, claustrum; $G L$, lateral geniculate; GP, globus pallidus; Hipp, hippocampus; Put, putamen; $T O$, optic tract.

fundus were removed for most of the extent of the lesion. Two of the animals sustained slight bilateral damage to the lateral nucleus of the amygdala, and one animal sustained slight unilateral damage. In all five animals, the hippocampus was undamaged through its extent. The TSC monkey sustained cortical damage comparable to that of the TS monkeys, but the white matter of the temporal stem was intact. (Fig. $2 B$ ).

\section{Experiment 1A-Visual Discrimination Learning}

Subjects. The subjects were four monkeys with conjoint removal of hippocampus and amygdala $(\mathrm{H}-\mathrm{A})$, five monkeys with lesions of temporal stem white matter (TS), one control monkey for the temporal stem lesion (TSC), and three normal monkeys (N).

Apparatus and procedure. All monkeys were tested in a modified Wisconsin General Test Apparatus (WGTA). The experimenter sat behind a one-way screen facing a tray, which contained three food wells spaced $16 \mathrm{~cm}$ apart, center to center, and $16 \mathrm{~cm}$ in front of the testing cage. Only the two lateral food wells were used. Between trials, the experimenter concealed the tray from the monkey by lowering an opaque door.

Visual pattern discrimination ( $\square$ versus + and $N$ versus $W$ ). All monkeys first learned to discriminate a $\square$ from $a+$ and then learned to discriminate $\mathrm{N}$ from $\mathrm{W}$. The patterns were made by pressing white tape to two identical blue plaques $(7.6 \mathrm{~cm}$ square). On each trial, the monkey was allowed to displace one of the plaques. A correct choice uncovered a raisin reward, and an incorrect choice uncovered an empty food well. Each monkey was always rewarded for choosing the same pattern, but which pattern was correct varied from monkey to monkey. From trial to trial, each plaque appeared over the left and right food wells with equal probability (Gellerman, 1933). After each choice, the opaque door was lowered, and the plaques and raisin reward were arranged for the next trial. The intertrial interval was 10 to 12 sec. Testing continued until a learning criterion of $90 \%$ correct was achieved for 2 consecutive days or until a maximum of 1000 trials had been given. The first pattern $(\square$ versus + ) was administered for 20 trials per day. The second pattern ( $N$ versus $W$ ) was administered for 30 trials per day.

Results. Figure $3 A$ shows the average score for acquisition of both pattern discrimination problems. The group with temporal stem lesions required a median of 800 trials to learn these problems, significantly worse than the 310 trials required by the normal group ( $U=$ $\mathrm{O}, p<0.05$ as measured by either trials or errors to criterion) and also worse than the 345 trials required by monkeys with $\mathrm{H}$-A lesions $(U=0, p<0.01$ for both trials and errors). Compared to normal monkeys, the $\mathrm{H}$ A group was unimpaired as measured by trials to criterion $(U=4, p>0.1)$ and mildly impaired as measured by errors $(\mathrm{N}=99 ; \mathrm{H}-\mathrm{A}=110, U=\mathrm{O}, p<0.05)$. The single operated control monkey (TSC) learned the two problems in an average of 330 trials and 120 errors.

Figure $3 B$ shows the average learning curves for normal and H-A groups on each of the two pattern discrimination problems. This figure makes two points. First, aquisition of each pattern discrimination problem was an incremental process, moving from chance performance to criterion in a gradual, step-by-step fashion. Second, the learning impairment of the $\mathrm{H}$-A group was mild but, neverthless, consistent.

Further analysis of the performance of the three groups on pattern discrimination learning helped to explain the mild impairment exhibited by the H-A group (Fig. 4A). Using the combined scores of the two pattern tasks, we divided into four equal blocks the daily sessions required by each monkey to reach criterion and calculated the percentage of correct responses made in each block. In this way it was possible to calculate the percentage of correct responses in each of four quarters of the learning curve. (An arbitrary rule was applied when the number of sessions needed to reach criterion could not be divided evenly by four. The first and last blocks were always assigned the same number of sessions, and the second block was assigned one more session than the third.) 


\section{Pattern Discrimination Learning}
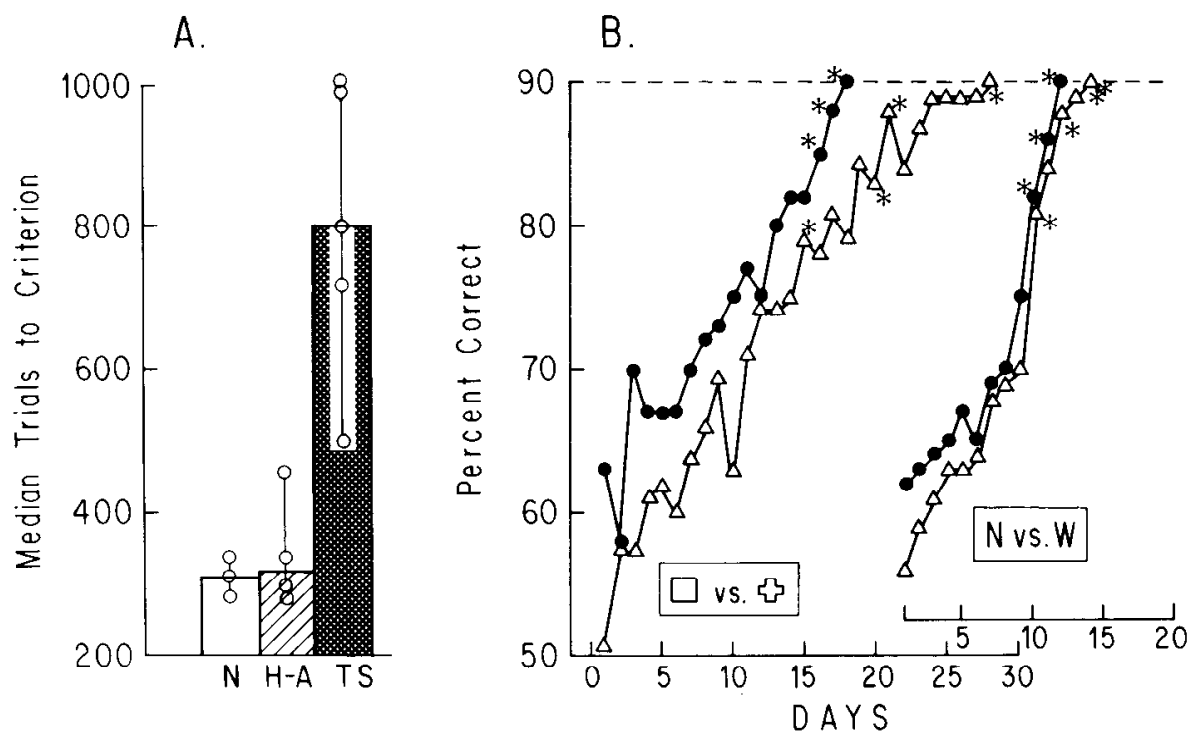

Figure 3. A, Average score for two pattern discrimination tasks by normal monkeys $(N)$, monkeys with conjoint hippocampalamygdala lesions $(H-A)$, and monkeys with temporal stem lesions (TS). Circles show individual scores for all monkeys. The TS group was impaired. The H-A group was normal as measured by trials to criterion and mildly impaired as measured by errors to criterion. $B$, Group learning eurves for the $\mathrm{N}$ (solid circles) and H-A (open triangles) groups on each of the two pattern discrimination tasks. For the first task, 20 trials were given each day. For the second task, 30 trials were given each day. The $\mathrm{H}$ A group was mildly impaired. * indicates the point in training when individual animals reached criterion performance.

From these data, two measures were derived: the percentage of correct responses during the first five trials of each day (averaged for each block) and the percentage of correct responses during the remaining trials of each day (averaged for each block). The findings to be described below for the first five trials of each test day were the same whether they were based on the first two, three, four, or five trials of each day.

Figure $4 A$ shows that monkeys with $\mathrm{H}$-A lesions performed poorly at the beginning of each test day, particularly during the first half of training, but performed normally once they had received the first five trials of each test day. By contrast, monkeys with TS lesions were impaired throughout training, both at the beginning of each test day and during the remaining trials of each day. Overall analyses of variance were performed for the normal versus H-A group and for the normal versus TS group. Tests of main effects (Kirk, 1968) were used where appropriate. The comparison between normal and $\mathrm{H}-\mathrm{A}$ groups revealed that the $\mathrm{H}$-A group performed more poorly overall $(F(1,5)=8.48, p<0.05)$. Analyses of main effects revealed that this difference was due entirely to the poor performance of the H-A group during the first five trials of each day (Fig. $4 A$, left, $\mathrm{F}(1,5)=40.52$, $p<0.001)$. This effect was especially prominent in the first and second blocks of training. The H-A group performed normally during the remaining trials of each test day, once the first five trials had been given (Fig. $4 A$, right, $\mathrm{F}(1,5)=4.73, p>0.1)$. There was also a significant effect of blocks $(\mathrm{F}(3,15)=56.75, p<0.001)$, indicating the gradual improvement in performance during training, and there was an interaction of group $\mathrm{X}$ block $(\mathrm{F}(3,15)=4.02, p<0.05)$.

The comparison between the normal and TS group revealed significant effects of group $(\mathrm{F}(1,4)=21.07, p$ $<0.01)$, block $(F(1,12)=33.28, p<0.001)$, and trials (first five versus remaining) $(\mathrm{F}(1,4)=33.51, p<0.01)$. Analysis of main effects revealed that the difference between groups was significant for the first five trials of each day $(F(1,4)=54.4, p<0.001)$, as well as for the remaining trials $(\mathrm{F}(1,4)=51.65, p<0.001)$. Thus, monkeys with TS lesions, unlike $\mathrm{H}-\mathrm{A}$ monkeys, performed poorly throughout training. This difference between TS and H-A monkeys was not a simple consequence of the impairment that TS monkeys exhibited in learning discrimination problems. First, the findings for TS monkeys were similar when only monkeys actually reaching criterion were included in the analysis. Second, since TS monkeys performed $70 \%$ correct, on average, at the completion of training, the data for H-A monkeys were reanalyzed to include test sessions only up to the point when $70 \%$ correct performance was reached. Both $\mathrm{H}$-A and TS monkeys performed poorly on the first five trials of the test days leading to the $70 \%$ performance level. Only the TS monkeys, however, were impaired as well on the remaining trials of each test day.

These data indicate that $\mathrm{H}-\mathrm{A}$ monkeys exhibited one kind of deficit in pattern discrimination learning, i.e., impaired performance on the first few trials of each day's session, but normal performance on the remaining trials of each session. The TS monkeys exhibited a different kind of deficit, i.e., impaired performance throughout each day's session on every day of training. This conclusion is also supported by a direct comparison of the $\mathrm{H}-\mathrm{A}$ and TS groups. The TS group performed more poorly overall $(\mathrm{F}(1,5)=6.07, p<0.05)$. Analysis of main effects indicated that there was no difference between groups during the first five trials of each day. The difference 

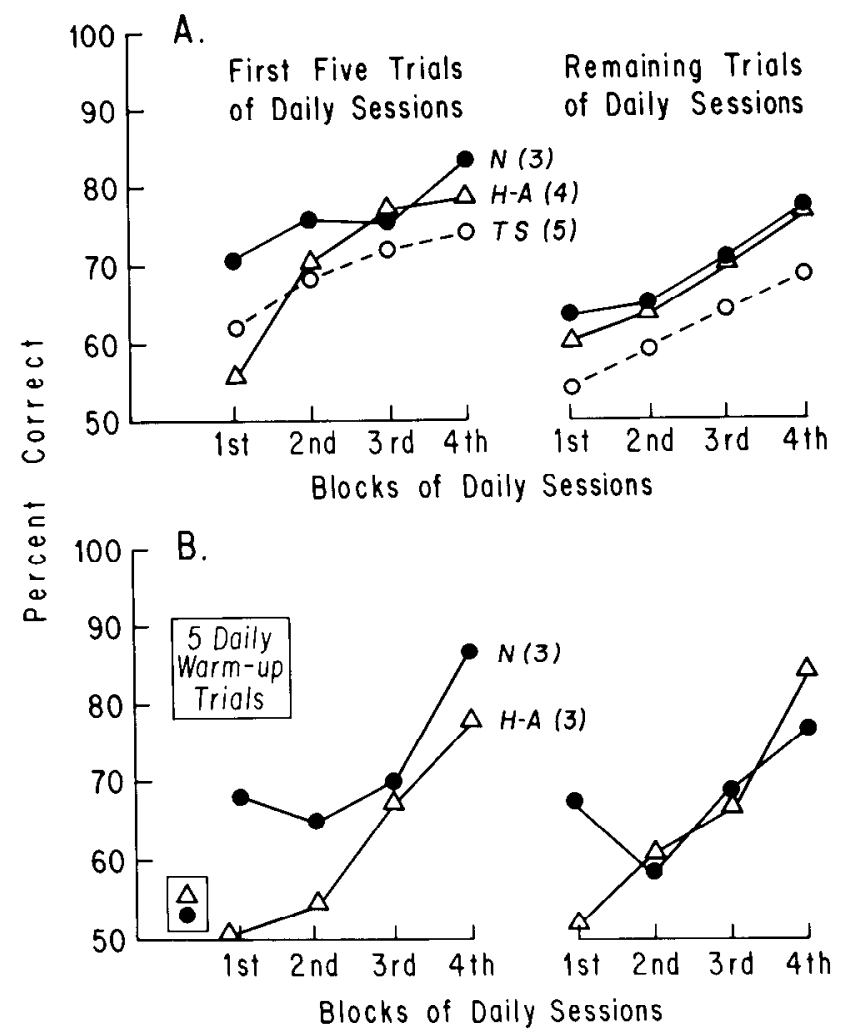

Figure 4. A, For two pattern discrimination tasks (Fig. 3), each animal's learning curve was divided into four quarters or blocks. The data show acquisition during the first, second, third, and fourth quarters of training. The left panel shows average performance for the first five trials of the daily sessions in each block. The right panel shows average performance for the remaining trials of the daily sessions in each block. $N$, normal; $H$-A, hippocampal-amygdala lesions; $T S$, temporal stem lesions. The TS group was impaired throughout training both at the beginning of the daily sessions as well as during the remaining trials of the daily sessions. The $\mathrm{H}$-A group performed poorly only at the beginning of daily sessions and performed normally on the remaining trials. $B$, Same as $A$, except that five task-irrelevant trials were presented at the beginning of each test day. This manipulation had no effect on the results.

between groups was due to the poorer performance of the TS group during the remaining trials of each day (Fig. $4 A$, right, $\mathrm{F}(1,5)=36.6 p<0.001$ ).

No systemic relationship was found between the presence or absence of damage to extrahippocampal-amygdala structures and the performance of the $\mathrm{H}$-A monkeys on the visual discrimination tasks. In particular, the extent of damage to visual area TE (Bonin and Bailey, 1947) in temporal neocortex did not appear to contribute in any systematic way to the overall performance scores of the H-A monkeys on the visual tasks or to their performance on the first five trials of each day.

\section{Experiment 1B}

The finding that $\mathrm{H}-\mathrm{A}$ monkeys performed poorly only on the first few trials of each testing day suggested either that monkeys were forgetting between sessions some of what they had previously learned, or that they were disoriented in some way at the start of each training session and required five trials to reorient to the task.
The first explanation supposes that their difficulty was specific to the task being trained and that five training trials with this task were needed each day to bring the animals back to normal performance. The second explanation supposes that the difficulty was not with the task itself, but with more general factors in the training situation. By this view, the $\mathrm{H}-\mathrm{A}$ monkeys might need a short warm-up period in the testing apparatus before they can perform at a normal level.

To choose between these alternatives, $\mathrm{H}$ - $\mathrm{A}$ and normal monkeys were given two additional pattern discrimination problems. Each day's training session was preceded by five warm-up trials involving novel test objects irrelevant to the particular discrimination problem being trained.

Methods. Approximately 18 months after completion of the two pattern discrimination tasks of experiment $1 \mathrm{~A}$, monkeys in the H-A group and the normal monkeys were given two additional pattern discrimination problems ( $F$ versus $\$$ and $M$ versus $C$ ). At this time, all monkeys had identical testing histories. The two new discrimination problems were given in sequence, 30 trials each day. Unlike the procedure for experiment 1A, the daily testing sessions were always preceded by five warmup trials. The warm-up trials were intended to reorient the monkeys to the testing situation, without providing specific information relevant to the discrimination problems. Monkeys were given five trials, each of which allowed a choice between two different, unfamiliar objects. Five new pairs of objects were used for each daily session, and the raisin reward was placed randomly under the left or right food well, so that there was no "solution" to this portion of the day's session. Following these warm-up trials, the appropriate pattern discrimination task was administered. Because one $\mathrm{H}$-A monkey had been sacrificed for histological analysis, only three of the four original $\mathrm{H}$-A monkeys participated in these tests.

Results and discussion. The results for these two pattern discrimination problems are shown in Figure $4 B$. The warm-up trials had little effect on acquisition (compare to Fig. $4 A$ ) and did not eliminate the deficit exhibited by $\mathrm{H}$-A monkeys. As would be expected, all monkeys performed at chance on the "insoluble" warm-up trials. The H-A group again exhibited a mild impairment in acquiring the two discrimination problems (H-A group: 435 trials, 149 errors; $\mathrm{N}$ group: 285 trials, 108 errors, $p<$ 0.05 for errors). The mild impairment of the $\mathrm{H}$-A group was again due to poor performance during the first five trials of each day $(\mathrm{F}(1,4)=9.4, p<0.05)$. Performance was normal for the remaining trials of each day $(F(1,4)$ $=0.39, p>0.1$ ).

Since five warm-up trials had no effect on pattern discrimination learning, the deficit in acquisition exhibited by H-A monkeys must be related to the task itself and to a difficulty, not shared with normal monkeys, in maintaining performance levels between the end of one session and the beginning of the next one. The findings from experiments $1 \mathrm{~A}$ and $1 \mathrm{~B}$, taken together, suggest that monkeys with $\mathrm{H}-\mathrm{A}$ lesions had difficulty with pattern discrimination learning because they forgot each day some of what they had learned during the previous day. Nevertheless, visual discrimination learning can be 
accomplished relatively successfully by monkcys with $\mathrm{H}$ A lesions. In the case of the two-dimensional pattern discrimination, which requires hundreds of trials to learn, performance must depend largely on a process that is not affected by $\mathrm{H}-\mathrm{A}$ lesions.

\section{Experiment 2}

In contrast to pattern discrimination, a discrimination between three-dimensional objects can be learned quickly by normal monkeys, and when pairs of objects are specially selected for their distinctiveness (Mahut et al., 1981), monkeys can learn to discriminate between them in fewer than 50 trials. The increase in discriminability between stimuli in such a task should greatly reduce the demand for the gradual tuning in of the relevant stimulus dimension. Learning the task should then depend primarily on other components, e.g., learning which stimulus is rewarded. We have supposed that the identity of the rewarded stimulus is learned more as a fact than as a skill and that this learning should be impaired by $\mathrm{H}$-A lesions. The next experiment tested this hypothesis directly.

\section{Methods}

Subjects. The subjects were 11 monkeys that participated in experiment $1 \mathrm{~A}(\mathrm{H}-\mathrm{A}=4 ; \mathrm{TS}=4 ; \mathrm{N}=3)$. One TS monkey had been sacrificed for histological analysis.

Apparatus and procedures. Using the WGTA, four separate object discrimination tasks were administered. Two of them were administered immediately after all animals completed the first two pattern discrimination problems (experiment 1A), and the two others were administered approximately 8 months later before the start of experiment 1B. Thus, all four object discrimination tasks were administered between the two pattern discrimination tasks of experiment $1 \mathrm{~A}$ and the two pattern tasks of experiment 1B. The four object discrimination tasks were modeled after ones developed by Jarvik (1953, 1956), who demonstrated that monkeys could acquire visual discrimination tasks rapidly in a single session when the discriminanda themselves were the reward (e.g., bread dyed red and flavored with sugar versus bread dyed green and flavored with vinegar). Accordingly, one of our discrimination tasks required monkeys to choose one of two peanut half-shells, dyed red or green. The correct shell, which was red for some animals and green for others, contained a clump of raisins wedged into the peanut shell cavity. When the monkey made its choice, it had in hand a peanut shell filled with raisins or a peanut shell that was empty. The other three tasks similarly involved two different objects, one of which was filled with raisins. Each discrimination pair was administered for two daily sessions of 20 trials each, the correct stimulus appearing over the left and right food wells in a predetermined order (Gellerman, 1933). Following a 48-hr delay, a third session of 20 trials was given. Although a fixed number of trials was given (20 per session on 3 different days), an animal was considered to have learned the task if during a daily session it achieved a successful run of 9 correct trials out of 10 (90\% correct).

\section{Results and discussion}

Figure $5 A$ shows the number of trials needed to achieve a run of 9 out of 10 correct trials during daily test sessions. By this measure, normal animals required a median of 9 trials to learn these tasks, the TS group required 15 trials, and the $\mathrm{H}-\mathrm{A}$ group required 30 trials. (Two H-A monkeys that did not achieve the learning criterion within 40 trials were assigned a score of 40 for this analysis.) This measure of trials to criterion for object discrimination learning permitted a comparison with the results for pattern discrimination learning reported in experiment $1 \mathrm{~A}$ (see Fig. $3 A$ ). To make this comparison more directly, we reanalyzed the data from experiment $1 \mathrm{~A}$ using the same learning criterion of 9 correct trials out of 10 that was used in the present experiment. By this analysis, the median trials to criterion required to learn the two pattern discriminations of experiment $1 \mathrm{~A}$ were as follows: $\mathrm{H}-\mathrm{A}, 272$ trials; normals, 250 trials; TS, 460 trials. Clearly H-A monkeys could learn pattern discriminations almost normally. Yet the same H-A monkeys were severely impaired at learning object discriminations, as shown in experiment 2 .

Figure $5 B$ shows the performance of each of the three groups on the three 20-trial sessions. Each daily session is presented as four blocks of five trials each. These data show the impaired performance of the H-A group (18 errors in 60 trials), compared to both the TS group (11 errors) and the normal group (9 errors). An analysis of variance revealed an effect of group $(F(2,8)=18.19, p$ $<0.001)$, days $(\mathrm{F}(2,16)=58.19, p<0.001)$, and blocks $(\mathrm{F}(3,24)=42.65, p<0.001)$ but no significant interactions. Further analysis using the Newman-Keuls test (Kirk, 1968) showed that the H-A group was significantly worse across all days than either the normal $(p<0.05)$ or the TS $(p<0.05)$ groups and that the TS group did not differ from the normal group.

The good performance of the TS monkeys in acquiring and retaining object discriminations might seem surprising in view of the difficulty that these monkeys exhibited in acquiring pattern discriminations. The temporal stem contains afferents and efferents of area TE (interotemporal cortex), and area TE is known to be involved in visual information processing (Milner, 1954; Mishkin, 1954; Gross, 1973a, b). Damage to area TE impairs pattern discrimination learning but exerts less of an effect on discriminations involving stimuli that differ in many features (e.g., color, size, shape, texture) (Gross, $1973 \mathrm{a}, \mathrm{b})$.

In the case of the relatively difficult two-dimensional pattern discrimination tasks studied in experiment 1 , monkeys with H-A lesions exhibited a mild impairment, which was due entirely to poor performance during the first few trials of each test day. By contrast, in the case of the relatively easy object discriminalion tasks studied in experiment 2, monkeys with $\mathrm{H}$-A lesions exhibited a striking impairment throughout each test day and never performed as well as normal monkeys.

These findings support the suggestion that discrimination performance can succeed in monkeys with $\mathrm{H}-\mathrm{A}$ lesions only when the task depends primarily on skill learning. The object discrimination task used in experi- 

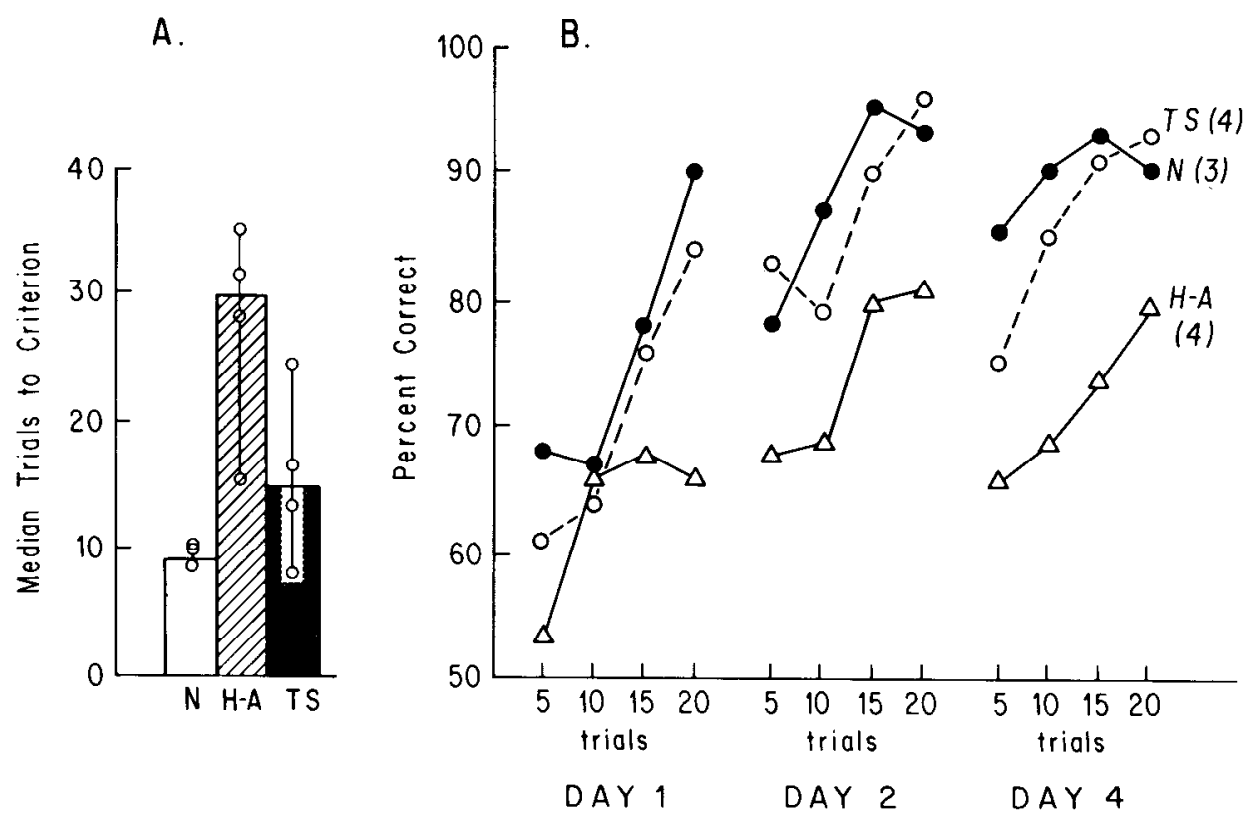

Figure 5. A, Average score for four separate object discrimination tasks by normal monkeys $(N)$, monkeys with conjoint hippocampal-amygdala lesions $(H-A)$, and monkeys with temporal stem lesions $(T S)$. Circles show individual scores for all monkeys. $B$, Average performance in five-trial blocks for four separate object discrimination tasks. Monkeys were given two daily sessions of 20 trials with each of the four object pairs (day 1 and day 2). Two days later, an additional session of 20 trials was given (day 4). The four object discrimination tasks were administered between the two pattern discrimination tasks of experiment $1 \mathrm{~A}$ and the two pattern tasks of experiment $1 \mathrm{~B}$.

ment 2 minimized the skill-like component by making it as easy as possible for the monkeys to attend to the objects and to distinguish them. When the skill-like or procedural component of a task is minimal, other components of the task largely determine performance. We suggest that the deficit in $\mathrm{H}-\mathrm{A}$ monkeys in experiment 2 reflects their failure to acquire these other components, i.e., their failure to achieve an enduring memory for facts about the task such as which stimulus is the rewarded one. By this view, object discrimination learning requires, in part, a kind of learning that is data-based or declarative, rather than skill-based or procedural, and this kind of learning is impaired by $\mathrm{H}-\mathrm{A}$ lesions.

In learning pattern discriminations (experiment 1) and comparatively easy object discriminations (experiment 2 ), the same fact must be acquired, i.e., which stimulus is the rewarded one? If $\mathrm{H}$-A lesions impair the ability to learn facts, then one might expect the deficit to be similar in pattern discrimination learning and object discrimination learning. Yet the deficit was mild in the former task and severe in the latter. Pattern discrimination learning by the view developed here involves a major skill-like component that requires hundreds of trials to master. Accordingly, monkeys learning pattern discriminations have hundreds of opportunities to learn and remember which stimulus is rewarded. In this way, repetition may eventually permit learning to occur. Figure 4 shows that $\mathrm{H}-\mathrm{A}$ monkeys learning pattern discrimination tasks in experiment 1 were impaired to some degree as they learned the task and that this impairment disappeared during the final sessions of training. During object discrimination learning, which can be mastered quickly by normal monkeys, H-A monkeys were impaired but were able to improve their performance (Fig. 5). Two H-A monkeys even reached a criterion of 9 out of 10 trials correct on this task. It appears that normal monkeys learn easy object discrimination tasks so rapidly that $\mathrm{H}$-A monkeys have insufficient repetition with the stimuli to permit them to keep pace with normal performance. To put it another way, because this task involves minimal skill-like components, the task requires primarily the kind of capacity that is impaired in monkeys with $\mathrm{H}-\mathrm{A}$ lesions. Accordingly, H-A monkeys are severely impaired.

\section{Experiment 3-Motor skills}

\section{Subjects}

The subjects were three monkeys that had undergone conjoint removal of the hippocampus and the amygdala ( $\mathrm{H}-\mathrm{A})$ and three normal monkeys $(\mathrm{N})$ that served as unoperated controls.

\section{Apparatus and procedure}

All monkeys were tested in a modified WGTA. The experimenter sat behind a one-way screen facing the WGTA. Between trials the experimenter concealed the testing materials from the monkey by lowering an opaque door. All monkeys were tested first on the barrier task and then approximately 3 weeks later on the Lifesaver task.

Barrier task. The test material consisted of three rows 


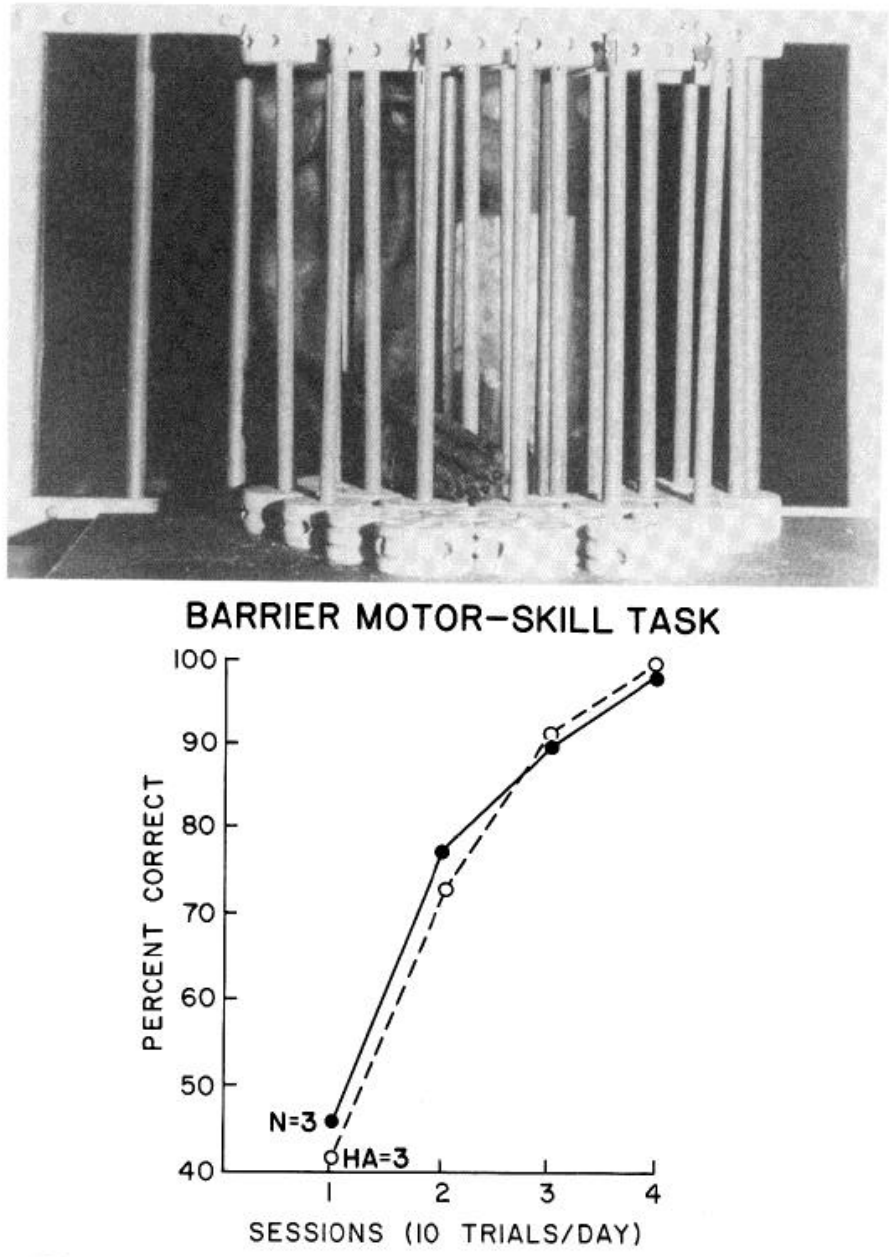

Figure 6. Monkeys with conjoint hippocampal-amygdala lesions $(H A)$ learned to manipulate a breadstick food reward through the barrier at the same rate as normal monkeys $(N)$.

deep of vertically arranged Tinkertoy sticks, which served as a barrier (Fig. 6). These were mounted in such a way that the space between the rows was $3.0 \mathrm{~cm}$, and the space between sticks in each row was $3.5 \mathrm{~cm}$. The barrier was placed in front of the monkey, $7.0 \mathrm{~cm}$ from the bars of the testing cage. At the start of a trial, a breadstick cut to a length of $8.0 \mathrm{~cm}$ was placed horizontally on a small platform just behind the barrier, from the monkey's perspective, and parallel to the front of the testing cage. To retrieve the breadstick, the monkey had to reach with its hand through the three rows of Tinkertoy sticks, pick up the breadstick, and then manipulate it back through the Tinkertoy barriers. To accomplish this, it was necessary to orient the breadstick appropriately and withdraw it slowly through the barrier. A trial ended when the breadstick broke against one of the Tinkertoy sticks or was dropped. In that case, the opaque door concealing the barrier from the monkey was lowered, and a new trial was readied. If the monkey succeeded in manuevering the unbroken breadstick through the barriers, he was allowed to eat it. The opaque door was then lowered and a new trial readied. Ten trials were given per day for 4 consecutive days.

Lifesaver task. This task was adapted from one described by Davis et al. (1956). The apparatus consisted of a horizontally oriented metal rod with two right angle bends, each approximately $10.0 \mathrm{~cm}$ from a center pole (Fig. 7). It was designed so that the experimenter could slide a candy Lifesaver (with a hole in the middle) onto either end of the rod and move it around the bend to the center pole. The center pole was placed in front of the monkey, $7.0 \mathrm{~cm}$ from the bars of the testing cage.

Prior to formal testing, monkeys were first pretrained to retrieve a candy Lifesaver, when the candy was placed directly at the end of the metal rod, where it could be removed without negotiating a bend. Following pretraining, which was accomplished by all monkeys in one session, formal testing was administered as follows. With the opaque door of the WGTA lowered, a Lifesaver was threaded onto the rod at the monkey's right and moved to the center pole. The opaque door was then raised, and the monkey was allowed $30 \mathrm{sec}$ to retrieve the Lifesaver by manuevering it from the center of the rod, around the bend, and off the end of the rod. If 30 sec elapsed before the monkey obtained the Lifesaver, the opaque door was lowered and the trial was reset with the Lifesaver at the center pole. If the monkey obtained the Lifesaver before

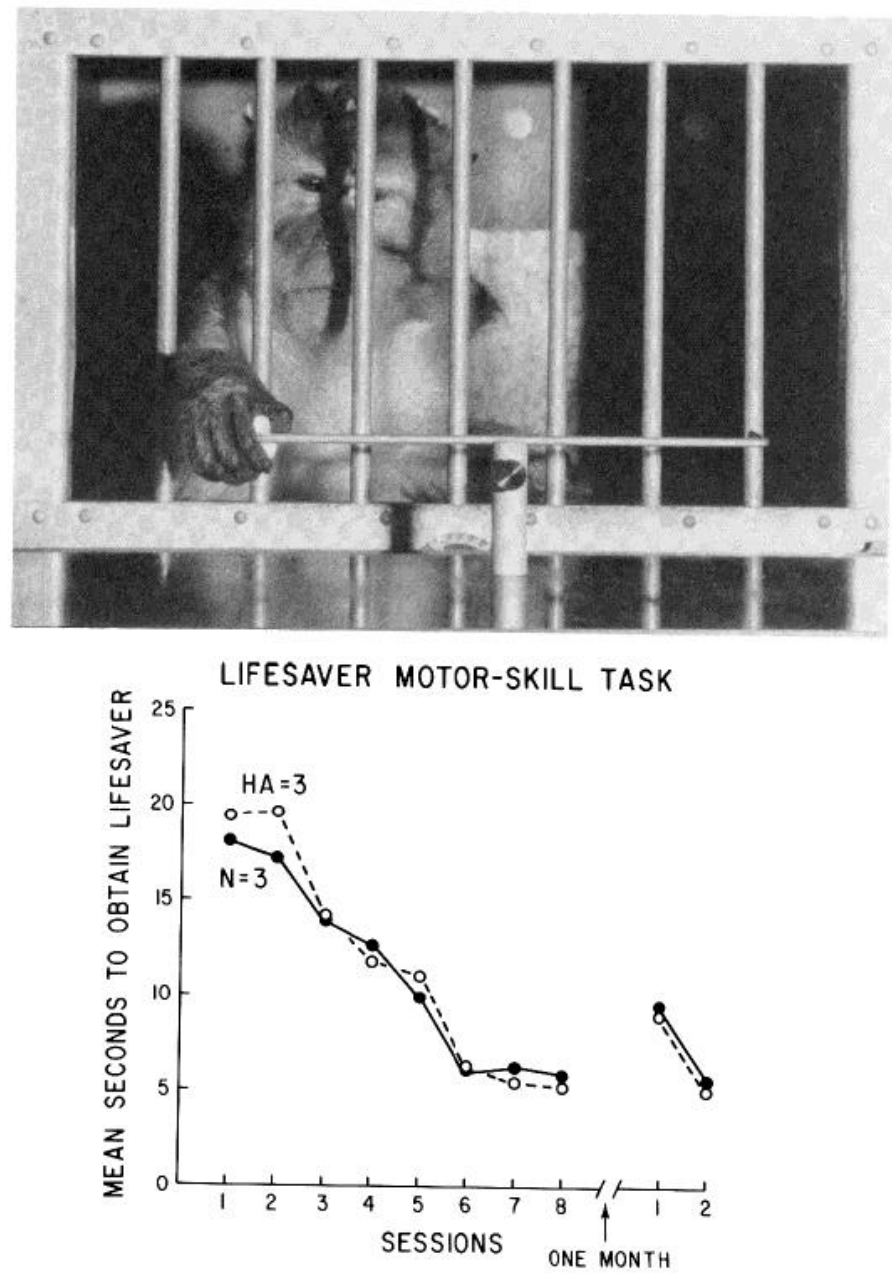

Figure 7. Monkeys with hippocampal-amygdala lesions $(H A)$ and normal monkeys $(N)$ learned to obtain a candy Lifesaver by maneuvering it along a metal rod and negotiating a $90^{\circ}$ bend. The rate of learning was identical in the two groups. After a 1-month interval, the H-A monkeys retained the skill as well as normal monkeys. 
the time limit, he was allowed to eat it. The opaque door was then lowered, and a new trial was begun. Six trials were administered every other day until eight sessions had been given. One month after the last session of initial learning, monkeys were retested by being given two additional sessions in 2 consecutive days.

\section{Results}

Barrier task. The percentage of daily trials on which the breadstick was obtained by the medial temporal and normal control groups is shown in Figure 6. A two-way analysis of variance revealed a significant effect of sessions $(F(3,12)=106, p<0.01)$, indicating that performance improved across the test days. There was no effect of group and no interaction of group $\times$ session (F's $<$ $1.0)$.

Detailed analyses of errors made during acquisition of the task were undertaken to determine if any differences could be found between groups. First, errorless performance was achieved by both groups at the same time. On days 1 and 2, no monkeys in either group made zero errors; on day 3 , one normal control and one H-A monkey made zero errors; on day 4, all three monkeys in each group made zero errors. Second, the two kinds of errors (breadstick broken or breadstick dropped) which terminated a trial occurred with the same frequency in each group. On day 1 both groups made more "broken" errors than "dropped" errors ( $62 \%$ versus $38 \%$, respectively, for the normal control group; $70 \%$ versus $30 \%$, respectively, for the H-A group); on day 2 the pattern reversed, both groups making more "dropped" errors than "broken" errors $(71 \%$ versus $29 \%$, respectively, for the normal control group; $88 \%$ versus $12 \%$, respectively, for the $\mathrm{H}$ A group); on day 3 , all of the errors made in each group (three for the normal controls and two for the H-A group) were "dropped" errors; on day 4, both groups were errorless. Finally, the groups performed identically, as measured by errors, on the first trial of each test day, which followed a 24-hr rest period. On the first trial of day 1 $(\mathrm{N}=1, \mathrm{H}-\mathrm{A}=0)$, day $2(\mathrm{~N}=0.66, \mathrm{H}-\mathrm{A}=0.33)$, day 3 $(\mathrm{N}=0.33, \mathrm{H}-\mathrm{A}=0)$, and day $4(\mathrm{~N}=0, \mathrm{H}-\mathrm{A}=0)$.

Lifesaver task. During initial learning of the Lifesaver task, both the H-A and the normal control groups reached asymptotic performance by day 6 (Fig. 7). A twoway analysis of variance indicated a significant effect of session $(\mathrm{F}(7,28)=3.9, p<0.01)$, indicating that performance improved across test days. There was no effect of group and no significant group $\times$ sessions interaction (F's $<2.0, p>0.1$ ). When retested 1 month after the last session of initial learning, performance of the two groups was equivalent (Fig. 4). The $\mathrm{H}-\mathrm{A}$ and $\mathrm{N}$ groups demonstrated the same level of performance on both days of retesting $(F(1,4)=3.5, p>0.1)$. Both groups reached the previously attained asymptotic level of performance in the second session, and there was no group $X$ session interaction $(F<1.0)$.

Detailed analyses of acquisition and retention performance by each group could not distinguish the normal control monkeys from the H-A monkeys. Specifically, the mean number of seconds to retrieve the Lifesaver on the first trial of each day was similar (controls $=(13.2 \pm$ $2.0 \mathrm{sec} ; \mathrm{H}-\mathrm{A}$ group $=10.1 \pm 1.5 \mathrm{sec}, \mathrm{F}(1,4)=2.0, p>$
0.1 . Separate analyses of each of the remaining five trials of each day showed that the average score for the two groups never differed by more than $3 \mathrm{sec}$.

\section{Discussion}

In an effort to bring into correspondence studies of human amnesia and the findings from monkeys with brain lesions in the areas implicated in human amnesia, we have addressed in two experiments the apparently anomalous results for visual discrimination tasks. In a third experiment, we addressed the question of whether motor skill learning, preserved in human amnesia, would also be preserved in operated monkeys. The principal findings were, first, that monkeys with conjoint lesions of the hippocampus and amygdala, that had previously been found impaired on a test sensitive to human amnesia (Zola-Morgan et al., 1982), exhibited only a mild impairment in learning relatively difficult pattern discrimination tasks. The second finding was that these operated monkeys exhibited a marked impairment in learning and remembering relatively easy object discrimination problems, which could be mastered by normal monkeys in a few trials. The third finding was that these same operated monkeys exhibited normal learning and retention of motor skills. These results can be understood in light of recent developments in the neuropsychology of memory.

Motor skill learning in monkeys. It has been known for some time that, despite their profound memory impairment, amnesic patients can under some circumstances exhibit good learning and retention across long intervals. The best known examples of this observation come from the learning of perceptuo-motor skills. Case H. M., for example, exhibited progressive learning of mirror tracing, rotary pursuit, and bimanual tracking across several days of testing (Milner, 1962; Corkin, 1968), despite reporting on each day that he had no memory of having performed the task before. In the present study we have demonstrated correspondence with these findings in human amnesia by showing that monkeys, that are by other measures amnesic, can, nevertheless, learn and retain motor skills. Learning curves and casual observation suggested that both the normal control monkeys and those with medial temporal lesions were acquiring a skill rather than suddenly learning the solution to the problem. In the Lifesaver task, for instance, both groups of monkeys pulled or spun the Lifesavers early in practice. As learning progressed, however, the movements became more appropriate, and ultimately the monkeys could remove the Lifesaver within a very few seconds without apparent effort.

Of particular importance was the fact that the operated monkeys learned at an entirely normal rate and performed in a way that was qualitatively and quantitatively indistinguishable from control subjects. Thus, acquisition of motor skills by monkeys with medial temporal lesions cannot be explained by continued and extensive repetition of information. If repetition were responsible for the gradual acquisition of a skill over many trials, then the operated monkeys should have been inferior to the normal control monkeys during the early learning trials and have caught up with the normal control mon- 
keys on later trials. Yet this did not occur. There were no significant differences between groups on any day of training. Moreover, there were no differences between groups on the first trial of each daily session. This observation for motor skill tasks demonstrates compellingly that some learning is spared in monkeys with medial temporal lesions and that this learning does not depend on the integrity of the medial temporal region. It should be emphasized that the success on the motor skill tasks by the operated monkeys was not due to recovery of function following surgery. Immediately following the retention of the Lifesaver task (experiment 3), all monkeys were administered two easy object discrimination tasks, like those used in experiment 2 . The results were similar to those in experiment 2 . The normal monkeys required a median of nine trials to learn the tasks, but the H-A group was impaired (median of 33 trials, $U=0$, $p<0.05$ ).

Pattern discrimination learning in monkeys as a skill. Human amnesia is characterized by a deficit in retaining information across delays. Because monkeys require many daily sessions to learn pattern discrimination tasks, the success of monkeys with $\mathrm{H}$-A lesions in learning these tasks has seemed difficult to reconcile with human amnesia (Orbach et al., 1960). However, we suggest that the neuropsychological facts of human amnesia, as we now understand them, provide an account of pattern discrimination in monkeys that can reconcile these findings with the human data. During the last 10 years, investigators have compiled a considerable list of tasks that are less clearly perceptuo-motor but that can elicit signs of retention in patients who by other indications are profoundly amnesic (Cohen, 1981, 1984; Moscovitch, 1982; Weiskrantz, 1982; Wood et al., 1982; Graf et al., 1984). One good example is the demonstration that amnesic patients improved at a normal rate their skill at learning to read mirror-reversed words over a 3-day period and then retained the skill at a normal level 3 months later (Cohen and Squire, 1980). Yet many of the patients did not remember having worked at the task before, and all were amnesic for the particular words that they read. Similar findings have recently been demonstrated using a complex cognitive problem-solving task, the Tower of Hanoi problem (Cohen and Corkin, 1981).

Patients with both diencephalic and medial temporal lesions are capable of acquiring the skills or procedures needed for mirror reading, but they cannot acquire facts about the world, the outcomes, or results of having used these skills, i.e., the fact that they had been tested or the ability to recognize as familiar the words that they had read. These findings have suggested a distinction, developed in more detail elsewhere (Cohen, 1981, 1984; Squire, 1982; Squire and Cohen, 1984), between skills, which are spared in amnesia, and information based on specific facts, or outcomes of engaging in skills, which are impaired in amnesia.

It is our view that monkeys with $\mathrm{H}$-A lesions succeed at pattern discrimination learning in the same way that amnesic patients, including case $\mathrm{H}$. M., are able to learn cognitive skills. The results of the present study supported this view in two ways. First, learning was gradual
(Fig. $3 B$ ), as it is in human skill learning (Anderson, 1980). It is difficult to grasp intuitively what it means for an animal to move gradually from performing a discrimination task at $50 \%$ correct, then $60 \%$, then $70 \%$, then $80 \%$, etc. Adult human subjects working at similar tasks do not perform in this way. They learn in an almost all-or-none fashion, moving quickly from chance to perfect performance as soon as the relevant stimulus dimension is discovered. Perhaps a discrimination task that could be acquired gradually by humans and that might have skill-like properties would be learning to discriminate between different kinds of wine or learning to discriminate between the styles of different artists.

A second way in which pattern discrimination learning in monkeys resembled skill learning in humans was that there was no transfer between different discrimination problems. Stimulus dimensions, and the procedures involved in tuning them in, are taken to be rather specific to individual discrimination tasks. To the extent that stimulus dimensions are general (e.g., attend to the pattern, not to its color), there should be considerable positive transfer between successive pattern discrimination tasks. Yet in experiment 1, normal monkeys exhibited no positive transfer between the two tasks (first task: $\overline{\mathrm{x}}$ $=340$ trials, 91 errors; second task: $\overline{\mathrm{x}}=300$ trials, 96 errors). Indeed, it is a common finding that monkeys do not show positive transfer from one visual discrimination problem to the next (Harlow, 1944; Schrier and Harlow, 1957). Accordingly, whereas the learning of pattern discriminations by monkeys may well include the acquisition of some general information, the major work of the task would seem to be the selecting or tuning in of features specific to the stimuli to be discriminated (e.g., $\square$ versus + or $N$ versus $W$ ). In humans, skill learning can also be very specific. For example, practice in reading sentences typed in an unfamiliar style or orientation did not benefit subjects reading other sentences in a different, unfamiliar style or orientation (Kolers, 1975).

Our interpretation of pattern discrimination learning as a skill is consistent with the results of many other studies showing at most a mild impairment in pattern discrimination learning for monkeys with $\mathrm{H}-\mathrm{A}$ lesions (see Squire and Zola-Morgan, 1983 for a review of this literature). Moreover, monkeys with lesions of other brain regions that have been implicated in human amnesia, e.g., medial thalamus, also perform pattern discrimination tasks successfully, despite failing at other tasks that are sensitive to human amnesia (Isseroff et al., 1982; Zola-Morgan and Squire, 1982; Aggleton and Mishkin, 1983a,b).

Our interpretation of pattern discrimination learning does not suppose that all of the task is learned as a skill. Some part of the task (e.g., which stimulus is rewarded) might be learned as a fact or as an item of information in memory, and this part of the task should be affected in amnesia. This expectation was confirmed by the performance of H-A monkeys (Fig. 4, $A$ and $B$ ) during acquisition of the pattern discrimination tasks in experiments $1 \mathrm{~A} / 1 \mathrm{~B}$. The mild deficit in discrimination learning exhibited by the operated monkeys was accounted for entirely by their poor performance on the first five trials of each testing day. On the remaining trials of each 
testing day the operated monkeys performed like normal monkeys. These data indicate that the operated monkeys tended to forget some of what they had learned during each previous day. The results from experiment $1 \mathrm{~B}$, involving warm-up trials, showed further that what was forgotten each day was specific to the discrimination problem being trained. As training progressed, operated monkeys eventually reached a point where they no longer exhibited a deficit on the first five trials of each new test day. Apparently, after extensive repetition with the stimuli, operated monkeys could carry over their learning from day to day in a normal way.

Object discrimination learning in monkeys. When pairs of objects are specially selected for their discriminability, the role of skill learning or procedural learning (i.e., the gradual tuning in of the relevant stimulus dimension) should be greatly reduced. Correspondingly, learning data-based or declarative information (e.g., which stimulus is correct) becomes the major work of the task. By this formulation, an object discrimination that takes only 10 to 20 trials to learn should be expected to be more sensitive to the effects of medial temporal lesions than a pattern discrimination that takes $200-300$ trials to learn. This expectation was confirmed by the impairment of $\mathrm{H}-\mathrm{A}$ monkeys in experiment 2. A similar finding has recently been reported for monkeys with either hippocampal or conjoint hippocampal-amygdala lesions in both the visual and tactual modalities (Mahut et al., 1981).

We have recently reviewed the findings for 46 different two-choice discrimination tasks, as performed by monkeys with medial temporal lesions (Squire and ZolaMorgan, 1983). Of these, 21 were learned by normal monkeys in an average of 40 trials, and in 10 of these 21 tasks operated monkeys were mildly or severely impaired. The remaining 25 tasks required an average of 200 trials for normal monkeys to learn, and only four of the tasks yielded any sign of impairment in operated animals. This analysis strongly supports the present findings that discrimination tasks requiring only a few trials to learn should bring out an impairment in monkeys with medial temporal lesions more reliably than discrimination tasks that require many trials to learn.

The present findings, and the analysis of discrimination tasks presented here, make one additional point about the behavioral effects of $\mathrm{H}$-A lesions. The deficit cannot be attributed to task difficulty or task complexity. In the present study, monkeys with $\mathrm{H}$-A lesions were especially impaired on tasks that normal monkeys found easy; they were much less impaired on tasks that normal monkeys found difficult.

Animal models of human amnesia. It seems fair to say that it has been uncertainty about which tasks are appropriate to detect amnesia, more than any other factor, that has impeded efforts to establish an animal model of human amnesia. A proposal founded recently in studies of human amnesia distinguishes between procedural or skill-based learning, which is preserved in amnesia, and declarative or data-based learning, which is impaired (Cohen, 1981, 1984; Squire, 1982; Squire and Cohen, 1984). Here we have applied this distinction to motor skill learning and to visual discrimination learning in monkeys with medial temporal lesions and have shown how the data for both monkeys and humans can be brought into correspondence. An important part of this argument is the contention that pattern discrimination learning in monkeys resembles in many respects motor and cognitive skill learning in humans and, therefore, should not be severely affected by medial temporal lesions.

The data presented here, together with other recent studies in the monkey (Mishkin, 1978; Mahut et al., 1981, 1982; Mishkin et al., 1982; Zola-Morgan et al., 1982 ), identify a behavioral profile that signifies amnesia. Tasks are now available that are sensitive to human amnesia and that demonstrate an impairment in operated monkeys. Moreover, recent findings demonstrating the striking selectivity of human amnesia can explain why certain other tasks do not yield an impairment in operated monkeys. These developments take us a considerable way toward the establishment of an animal model of human amnesia. The present finding that $\mathrm{H}-\mathrm{A}$ lesions in monkeys caused a deficit that resembles human amnesia does not, of course, prove that lesions to both structures are required to produce this deficit. Although there are supporting data for this point of view (Mishkin, 1978; Mishkin et al., 1982), other studies in monkeys (Mahut et al., 1981, 1982) have found that damage to hippocampus alone can also cause a substantial memory impairment (for review of this issue, see Squire and ZolaMorgan, 1983). Further study is needed to resolve this question.

Study of the neurology of memory in monkey and man is nearing a point where it should be possible to identify the specific brain regions which when damaged caused amnesia. This information will be particularly useful because the study of human amnesia has already taught us a great deal about the function of this yet to be specified brain system (cf. Milner, 1972; O'Keefe and Nadel, 1978; Mishkin, 1982; Squire, 1982; Weiskrantz, 1982; Squire et al., 1983). This means that it may soon be possible to undertake neurobiological studies of memory, involving specific brain areas and increasingly molecular levels of analysis, while still maintaining a link both to behavioral memory and to the body of neuropsychological facts that describe its organization in the brain.

\section{References}

Aggleton, J. P., and M. Mishkin (1983a) Visual recognition impairment following medial thalamic lesions in monkeys. Neuropsychologia 21: 189-197.

Aggleton, J. P., and M. Mishkin (1983b) Memory impairments following restricted medial thalamic lesions in monkeys. Exp. Brain Res., in press.

Anderson, J. R. (1980) Cognitive Psychology and Its Implications, R. C. Atkinson, J. Freedman, G. Lindzey, and R. F. Thompson, eds., W. H. Freeman and Co., San Francisco.

Anzai, Y., and II. A. Simon (1979) The theory of learning by doing. Psychol. Rev. 86: 124-140.

Baddeley, A. (1982) Implications of neuropsychological evidence for theories of normal memory. In The Neuropsychology of Cognitive Function D. E. Broadbent and L. Weiskrantz, eds., pp. 59-72, The Royal Society, London.

Barbizet, J. (1970) Human Memory and Its Pathology, W. H. 
Freeman and Co., San Francisco.

Bartlett, F. C. (1932) Remembering, Cambridge University Press, Cambridge, England.

Bonin, G. V., and P. Bailey (1947) The Neocortex of Macaca mulatta, University of Illinois Press, Urbana.

Bruner, J. S. (1969) Modalities of memory. In The Pathology of Memory, G. A. Talland and N. C. Waugh, eds., pp. 253259, Academic Press, Inc., New York.

Cermak, L. S. (1982) Human Memory and Amnesia, Lawrence Erlbaum Associates, Hillsdale, NJ.

Cohen, N. J. (1981) Neuropsychological evidence for a distinction between procedural and declarative knowledge in human memory and amnesia. Ph.D. thesis, University of California, San Diego.

Cohen, N. J. (1984) Preserved learning capacity in amnesia: Evidence for multiple memory systems. In The Neuropsychology of Memory, N. Butters and L. R. Squire, eds., Guilford Press, New York, in press.

Cohen, N. J., and S. Corkin (1981) The amnesic patient H. M.: Learning and retention of a cognitive skill. Soc. Neurosci. Abstr. 7: 235.

Cohen, N. J., and L. R. Squire (1980) Preserved learning and retention of pattern analyzing skill in amnesia: Dissociation of knowing how and knowing that. Science 210: 207-209.

Corkin, S. (1968) Acquisition of motor skill after bilateral medial temporal-lobe excision. Neuropsychologia 6: 225-265.

Davis, R. T., A. A. McDowell, C. W. Deter, and J. P. Steele (1956) Performance of rhesus monkeys on selected laboratory tasks presented before and after a large single dose of whole body x-radiation. J. Comp. Physiol. Psychol. 49: 20-26.

Gaffan, D. (1974) Recognition impaired and association intact in the memory of monkeys after transection of the fornix. $J$. Comp. Physiol. Psychol. 86: 1100-1109.

Gellerman, L. W. (1933) Chance orders of alternating stimuli in visual discrimination experiments. J. Gen. Psychol. 42: $207-208$.

Graf, P., L. R. Squire, and G. Mandler (1984) The information that amnesic patients do not forget. J. Exp. Psychol. 10: 164178.

Gross, C. G. (1973a) Inferotemporal cortex and vision. Prog. Physiol. Psychol. 5: 451-482.

Gross, C. G. (1973b) Visual functions of inferotemporal cortex. In Handbook of Sensory Physiology, R. Jung, ed., SpringerVerlag, Berlin.

Harlow, H. F. (1944) Studies in discrimination learning by monkeys. I. The learning of discrimination series and the reversal of discrimination series. J. Gen. Psychiatry 30: $3-$ 12.

Harlow, H. F. (1950) Analysis of discrimination learning by monkeys. J. Exp. Psychol. 40: 26-39.

Horel, J. A. (1978) The neuroanatomy of amnesia: A critique of the hippocampal memory hypothesis. Brain 101: 403-445.

Horel, J. A., and L. J. Misantone (1976) Visual discrimination impaired by cutting temporal lobe connections. Science 193: 336-338.

Isaacson, R. L. (1972) Hippocampal destruction in man and other animals. Neuropsychologia 10: 47-64.

Isseroff, A., H. E. Rosvold, T. W. Galkin, and P. S. GoldmanRakic (1982) Spatial memory impairments following damage to the mediodorsal nucleus of the thalamus in rhesus monkeys. Brain Res. 232: 97-113.

Iversen, S. D. (1976) Do hippocampal lesions produce amnesia in animals? Int. Rev. Neurobiol. 19: 1-49.

Jarvik, M. E. (1953) Discrimination of colored food and food signs by primates. J. Comp. Physiol. Psychol. 46: 390.

Jarvik, M. E. (1956) Simple color discrimination in chimpanzees: Effect of varying contiguity between cue and incentive. J. Comp. Physiol. Psychol. 49: 492.
Kirk, R. E. (1968) Experimental Design: Procedures for the Behavioral Sciences, Brooks/Cole Publishing Co., Belmont, CA.

Kolers, P. A. (1975) Specificity of operations in sentence recognition. Cognitive Psychol. 7: 289-306.

Lashley, K. S. (1938) The mechanism of vision. XV. Preliminary studies of the rat's capacity for detail vision. J. Gen. Psychol. 18: 123-193.

Lovejoy, E. (1968) Attention in Discrimination Learning, Holden-Day, San Francisco.

Mahut, H., M. Moss, and S. Zola-Morgan (1981) Retention deficits after combined amygdalo-hippocampal and selective hippocampal resections in the monkey. Neuropsychologia 19 . 201-225.

Mahut, H., S. Zola-Morgan, and M. Moss (1982) Hippocampal resections impair associative learning and recognition memory in the monkey. J. Neurosci. 2: 1214-1229.

Milner, B. (1954) Intellectual function of the temporal lobes. Psychol. Bull. 51: 42-62.

Milner, B. (1962) Les troubles de la memoire accompagnant des lesions hippocampiques bilaterales. In Physiologie de l'Hippocampe, Centre National de la Recherche Scientifique, Paris.

Milner, B. (1972) Disorders of learning and memory after temporal lobe lesions in man. Clin. Neurosurg. 19: 421-446.

Mishkin, M. (1954) Visual discrimination performance following partial ablations of the temporal lobe. II. Ventral surface vs. hippocampus. J. Comp. Physiol. Psychol. 47: 187-193.

Mishkin, M. (1978) Memory in monkeys severely impaired by combined but not by separate removal of amygdala and hippocampus. Nature 273: 297-298.

Mishkin, M. (1982) A memory system in the monkey. Philos. Trans. R. Soc. Lond. Biol. 298: 85-95.

Mishkin, M., B. J. Spiegler, R. C. Saunders, and B. L. Malamut (1982) An animal model of global amnesia. In Toward a Treatment of Alzheimer's Disease, S. Corkin, K. L. David, J. H. Growdon, E. Usdin, and R. J. Wurtman, eds., pp. 235247, Raven Press, New York.

Moscovitch, M. (1982) Multiple dissociations of function in amnesia. In Human Memory and Amnesia, L. Cermak, ed. pp. 337-370, Lawrence Erlbaum Associates, Hillsdale, NJ.

Moss, M., H. Mahut, and S. Zola-Morgan (1981) Concurrent discrimination learning of monkeys after hippocampal, entorhinal, or fornix lesions. J. Neurosci. 1: 227240.

O'Keefe, J., and L. Nadel (1978) The Hippocampus as a Cognitive Map, Oxford University Press, London.

Orbach, J., B. Milner, and 'I. Rasmussen (1960) Learning and retention in monkeys after amygdala-hippocampus resection. Arch. Neurol. 3: 230-251.

Oscar-Berman, M., and S. Zola-Morgan (1980) Comparative neuropsychology and Korsakoff's syndrome. I. Spatial and visual reversal learning. Neuropsychologia 18: 499-512.

Schrier, A. M., and H. F. Harlow (1957) Direct manipulation of the relevant cue and difficulty of discrimination. J. Comp. Physiol. Psychol. 50: 576-592.

Scoville, W. B., and B. Milner (1957) Loss of recent memory after bilateral hippocampal lesions. J. Neurol. Neurosurg. Psychiatry 20: 11-21.

Sidman, M., L. T. Stoddard, and J. P. Mohr (1968) Some additional quantitative observation of immediate memory in a patient with bilateral hippocampal lesions. Neuropsychologia 6: $245-254$.

Spence, K. W. (1936) The nature of discrimination learning in animals. Psychol. Rev. 43: 427-449.

Squire, L. R. (1981) Two forms of human amnesia: An analysis of forgetting. J. Neurosci. 1: 635-640.

Squire, L. R. (1982) Human memory: Neuropsychological and anatomical aspects. Annu. Rev. Neurosci. 5: 241-273. 
Squire, L. R., and N. J. Cohen (1981) Human memory and amnesia. In Proceedings of the Conference on the Neurobiology of Learning and Memory, J. McGaugh, G. Lynch, and N. Weinberger, eds., Guilford Press, New York, in press.

Squire, L. R., and S. Zola-Morgan (1983) The neurology of memory: The case for correspondence between the findings for man and non-human primate. In The Physiological Basis of Memory, Ed. 2, J. A. Deutsch, ed., pp. 199-267, Academic Press, Inc., New York.

Squire, L. R., N. J. Cohen, and L. Nadel (1983) The medial temporal region and memory consolidation: A new hypothesis. In Memory Consolidation, H. Weingartner and E. Parker, eds., Lawrence Erlbaum Associates, Hillsdale, NJ, in press.

Squire, L. R., N. J. Cohen, and J. Zouzounis (1984) Preserved memory in retrograde amnesia: Sparing of a recently acquired skill. Neuropsychologia, in press.

Sutherland, N. S., and N. J. Mackintosh (1971) Mechanisms of Animal Discrimination Learning, Academic Press, Inc., New York.

Victor, M., R. D. Adams, and G. H. Collins (1971) The Wernicke-Korsakoff Syndrome, F. Plum and F. H. McDowell, eds., F. A. Davis Co., Philadelphia.

Warrington, E. K., and L. Weiskrantz (1982) Amnesia: A disconmection syndrome? Neuropsychologia 20: 233-248.

Weiskrantz, L. (1971) Comparison of amnesic states in monkey and man. In Cognitive Processes of Non-Human Primates, L. E. Jarrard, ed., pp. 25-46, Academic Press, Inc., New York.

Weiskrantz, L. (1982) Comparative aspects of studies of amnesia. Philos. 'I'rans. K. Soc. Lond. Biol. 298: 97-109.

Wicklegren, W. A. (1979) Chunking and consolidation: A theoretical synthesis of semantic networks, configuring in conditioning, S-R v. cognitive learning, normal forgetting, the amnesic syndrome and the hippocampal arousal system. Psychol. Rev. 86: 44-60.

Wood, F., V. Ebert, and M. Kingbourne (1982) The episodicsemantic memory distination in memory and amnesia: Clinical and experimental observations. In Human Memory and Amnesia, L. Cermak, ed., pp. 167-193, Laurence Erlbaum Associates, Hillsdale, NJ.

Zeaman, D., and B. J. House (1963) The role of attention in retardate discrimination learning. In Handbook of Mental Deficiency: Psychological Theory and Research, N. R. Ellis, ed., McGraw-Hill, New York.

Zola-Morgan, S., and L. R. Squire (1982) Two forms of amnesia in monkeys: Rapid forgetting after medial temporal lesions but not diencephalic lesions. Soc. Neurosci. Abstr. 8: 24.

Zola-Morgan, S., L. R. Squire, and M. Mishkin (1982) The neuroanatomy of amnesia: Amygdala-hippocampus vs. temporal stem. Science 218: 1337-1339. 